\title{
INSERÇÃO E PERMANÊNCIA DE SURDOS NO MUNDO DO TRABALHO: ESTUDO EXPLORATÓRIO EM EMPRESAS DE UM MUNICÍPIO DO CENTRO-OESTE GOIANO
}

\section{INSERTION AND PERMANENCE OF DEAF WORKING WORK: EXPLORATORY STUDY ON COMPANIES IN A CITY OF A WEST GOIANO}

DOI: $\underline{\text { http://dx.doi.org/10.5965/1984317816012020193 }}$

$\begin{array}{r}\text { Rosângela Lopes Borges } \\ \text { Instituto Federal de Educação, Ciência e Tecnologia Goiano } \\ \text { rosalb2@hotmail.com }\end{array}$
$\begin{array}{r}\text { Jones Reis de Almeida } \\ \text { Faculdade de Caldas Novas } \\ \text { jones95reis@gmail.com }\end{array}$
Tainá de Sousa Siqueira
Faculdade de Caldas Novas
tainasiqueira00@hotmail.com

Marcos Fernandes Sobrinho Instituto Federal de Educação, Ciência e Tecnologia Goiano marcos.fernandes@ifgoiano.edu.br

\section{RESUMO}

O presente estudo abordou a temática da inclusão de pessoas surdas, pretendeu-se, entre outros, identificar quais as dificuldades que os surdos encontram para se inserirem no mundo do trabalho. Realizou-se uma pesquisa bibliográfica sobre esse assunto, e na sequência, uma pesquisa exploratória em seis empresas de um município do Centro-Oeste do estado de Goiás, Brasil, na tentativa de localizar os surdos que estavam empregados, o que não se concretizou. Durante a visita a essas organizações aplicamos um questionário com os responsáveis pelo departamento de Recursos Humanos (RH) e se constatou a presença de vagas ociosas a esse público, na região, o que constata que essas pessoas não estejam empregadas. Posteriormente, foram localizados três surdos em uma empresa da região circunvizinha a esta cidade e aplicou-se uma entrevista com eles, com auxílio de uma intérprete da Língua Brasileira de Sinais (LIBRAS). A análise dos dados se deu de maneira discursiva, tendo uma abordagem qualitativa, sendo possível evidenciar que existem barreiras antes e após a inclusão do surdo no mercado de trabalho, pois esses indivíduos não recebem o auxílio e orientação necessária para a sua inserção e permanência nessa empresa.

Palavras-chave: Surdo. Mundo do Trabalho. Empresas. Empregabilidade.

\section{ABSTRACT}

This study addressed the theme of inclusion of deaf people, and was intended, among others, to identify the difficulties that deaf people find to insert themselves in the world of work. A bibliographic research on this subject was carried out, and then, an exploratory research in six companies in a city of a west state of Goiás, Brazil, in an attempt to locate the deaf who were employed, which did not materialize. During the visit to these organizations we applied a questionnaire with those responsible for the department of Human Resources $(\mathrm{HR})$ and found the presence of idle vacancies to this public in the region, which shows that 
these people are not employed. Subsequently, three deaf people were located in a company from the surrounding region to this city and an interview was conducted with them, with the help of an interpreter of the Língua Brasileira de Sinais (LIBRAS). The data analysis was discursive, with a qualitative approach, and it is possible to show that there are barriers before and after the inclusion of the deaf in the labor market, as these individuals do not receive the help and guidance necessary for their insertion and permanence in this company.

Keywords: Deaf. Job market. Companies. Employability. Deafness.

\section{INTRODUÇÃO}

O O que nos motivou a realizar este estudo foi devido às aulas da disciplina de Língua Brasileira de Sinais - LIBRAS que tivemos, no curso de Administração. Com a agregação de novos conhecimentos em relação aos surdos, surgiu a curiosidade de saber como é na realidade a inclusão dessas pessoas no mundo do trabalho. Resolvemos, então, pesquisar mais profundamente a fim de evidenciar se as empresas realmente participam dessa inclusão ou apenas contratam para o cumprimento da lei.

É considerado surdo todo aquele que tem total ausência da audição, ou seja, que não ouve nada. É considerado deficiente auditivo todo aquele que a capacidade de ouvir, apesar da deficiência, é funcional com ou sem prótese auditiva. Tais terminologias serão mais bem esclarecidas no decorrer do texto.

No Brasil, segundo dados do censo demográfico, divulgados pelo Instituto Brasileiro de Geografia e Estatística (IBGE, 2010), cerca de 9,7 milhões de brasileiros e brasileiras declaram ter deficiência auditiva. Desse total, 2,1 milhões declararam ter deficiência auditiva severa. Há, também, o registro de 1,7 milhão que se considera com grande dificuldade para ouvir. De acordo com o Decreto $\mathrm{n}^{\circ}$ 5.296/04, para uma pessoa ser considerada com deficiência auditiva, é necessário "[...] perda bilateral, parcial ou total, de quarenta e um decibéis (dB) ou mais, aferida por audiograma nas frequências de $500 \mathrm{HZ}, 1.000 \mathrm{HZ}, 2.000 \mathrm{~Hz}$ e $3.000 \mathrm{~Hz}$ " (BRASIL, 2004, p. 01).

Mesmo com todo avanço tecnológico e cultural são grandes os obstáculos encontrados para a inserção e permanência do surdo no mundo de trabalho. Sabese que a Lei $n^{\circ}$ 8.213/91 estabelece contratação de pessoas com deficiência nas empresas com 100 ou mais funcionários, reservando de $2 \%$ a $5 \%$ das vagas para 
este público (BRASIL, 1991). No entanto, a lei não garante que esta inserção seja realmente inclusiva e de valor socioeconômico.

Perante tamanho preconceito e falta de conhecimento das empresas em relação às adaptações a serem feitas para receber esses funcionários (pessoas com deficiência), o número de contratações é bem pequeno. Soma-se a isso, a falta de capacitação e preparação destes para exercer funções mais elevadas no mundo do trabalho. E quando têm uma formação são alocados em funções de baixa remuneração que não condizem com suas formações, ou ainda, destinados às funções que não exigem comunicação, no caso dos surdos.

São muitos os obstáculos que os surdos enfrentam para se inserirem no mundo do trabalho. Agrava-se com a ausência de preparo do contratante em receber este candidato. Muitas organizações contratam pelo simples fato de serem obrigadas e estarem sujeitas a pagarem multa, de acordo com o artigo $10 \mathrm{~V}$, da Lei $\mathrm{n}^{\circ} 8.213 / 9$, que determina valor mínimo da multa, sendo reajustado anualmente.

É de extrema importância que este estudo evidencie as dificuldades e obstáculos que são encontrados pelo surdo na tentativa de se inserir no mundo do trabalho. Demonstrando os problemas que são enfrentados no seu cotidiano quando já inseridos e o que as empresas têm feito para se adaptar e receber esses funcionários, pois não se trata somente de contratar, é necessário um preparo de todos para o dia a dia, assim como a garantia de igualdade de condições, cobrança, reconhecimento e tratamento.

Isso tudo é mencionado na normativa 98 da Lei citada anteriormente, que propõe a fiscalização pela qualidade da contratação. Dessa maneira, levanta-se a seguinte problemática: Quais as dificuldades que os surdos encontram para se inserir e permanecer no mundo do trabalho? Que iniciativas o departamento de Recursos Humanos $(\mathrm{RH})$ tem tomado para facilitar a inclusão das pessoas com surdez? Esses empreendimentos são fiscalizados?

Esta produção científica tem como objetivo geral evidenciar as dificuldades e obstáculos que são encontrados pelos surdos no mundo do trabalho. Objetivamos ainda investigar se há fiscalização do Ministério do Trabalho (MT), nas empresas que contratam pessoas com deficiência; discutir sobre a importância da inclusão 
socioeconômica do Surdo; conhecer as dificuldades que os surdos encontram para serem contratados e se manterem empregados.

\section{INSERÇÃO E PERMANÊNCIA DO SURDO NO MUNDO DO TRABALHO}

Nesta seção, discutiremos sobre as características dos surdos e como se dá sua comunicação. Trataremos também da importância das terminologias corretas a serem utilizadas, principalmente as distinções entre surdo e deficiência auditiva. Abordaremos sobre a formação acadêmica e profissional do surdo e sua importância na empregabilidade desses indivíduos. Por fim, discorreremos sobre o papel da empresa no processo de inclusão socioeconômica do surdo.

\subsection{O surdo e sua comunicação}

A palavra comunicação pode levar a diversos caminhos. Porém no caso desse estudo, estamos falando mais precisamente da LIBRAS. Segundo a Lei $\mathrm{n}^{\circ}$ 10.436, de 24 de abril de 2002, em seu Artigo $1^{\circ}$, ela é reconhecida como meio legal de comunicação e expressão dos surdos. O mesmo documento explica ainda que essa língua é "[...] de natureza visual-motora, com estrutura gramatical própria, constitui um sistema linguístico de transmissão de ideias e fatos, oriundos de comunidades de pessoas surdas do Brasil” (BRASIL, 2002, p. 23).

Sobre a evolução da comunicação gestual consta que desde a Pré-História o homem já fazia uso de sinais com as mãos para se comunicar uns com os outros. Amaral e Santos (2017, p. 2) citam Vygotsky (1987-1934) que narra:

os homens pré-históricos trocaram a comunicação gestual pela comunicação oral, pela palavra, quando começaram a utilizar ferramentas; trabalhando com as mãos ocupadas, precisaram inventar uma alternativa para dialogar.

A comunicação oral se tornou então seu principal meio de comunicação, limitando a comunicação de sinais apenas para os surdos. Segundo Goldfeld (1997) apud Araújo, Silva e Sousa (2015),

Os surdos eram tratados com piedade e vistos como pessoas castigadas pelos deuses, sendo abandonados ou sacrificados. A 
surdez e a consequente mudez eram confundidas com uma inferioridade de inteligência. $E$ até o século quinze foi visto como uma pessoa primitiva que não poderia ser educado (ARAÚJO; SILVA; SOUSA, 2015, p. 1).

Com ideais tão pejorativos, a delonga foi grande até que tamanhas atrocidades deixassem de fazer parte de suas crenças. De acordo com Amaral e Santos (2017, p. 2), somente a partir de 1760, que a educação para os surdos ganhou um espaço na sociedade, através do professor Alemão Samuel Heinicke (1723-1790), o qual criou um método bastante peculiar para ensinar os surdos a "falar", e "[...] seus métodos eram estritamente orais onde ao invés de utilizar a visão como sentido principal, usou o paladar para associar a sons vocálicos a sabores". Apesar de tal ato ser impossível, acabou contribuindo para o desenvolvimento da comunicação de sinais no futuro.

Quem também se destacou na história, no ano de 1760 , foi o francês abade Charles Michel de L'Épée (1712-1789), por assumir a instrução de duas irmãs surdas. No Brasil, o Instituto Imperial dos Surdos-Mudos foi fundado em 1857, após Hernest Huet (surdo) obter apoio de Dom Pedro II, é conhecido, ainda hoje, como Instituto Nacional de Educação dos Surdos (INES). Mas o maior número de interessados em estudar a língua foi a partir de 1960, quando se teve um aumento dos diagnósticos de surdez (AMARAL; SANTOS, 2017).

Com tamanha conquista, foi possível que os surdos se tornassem bilíngues podendo aprender a Língua Brasileira de Sinais e a Língua Portuguesa (L2 - escrita). Porém, na atualidade a língua de sinais ainda é tratada como língua secundária, atrasando seu desenvolvimento, já que o período análogo para alfabetizar o surdo na língua de sinais se iguala ao da língua oral. Surdos que tiveram seu ensino com base na língua de sinais se tornaram mais conscientes na hora de aprender a L2 (AMARAL; SANTOS, 2017).

A Língua Brasileira de Sinais é o meio de comunicação natural da Comunidade Surda, desenvolvida a partir da língua de sinais francesa. Não existe um padrão linguístico universal, cada país tem sua própria composição, podendo mudar entre regiões de um mesmo país. Existe uma crença, por parte do ouvinte, que a língua de sinais seria o mesmo que mímica. Estudos revelam a incoerência de 
tal crença através da gramática que se aplica à língua de sinais composta por cinco parâmetros: 1) Configuração de mão. 2) Ponto de articulação. 3) Movimento. 4) Orientação. 5) Expressão facial. Enquanto, na mímica, são feitos vários gestos sem nenhum padrão. Através da língua de sinais é possível que os surdos expressem ideias, conceitos abstratos, emoções e sentimentos assim como os ouvintes (GESSER, 2009).

\subsection{A importância das terminologias corretas}

Até a atualidade, muitos nomes já foram utilizados para pessoas com deficiência como, por exemplo, deficiente, portadores de direitos especiais, pessoas especiais ou ainda pessoas com necessidades especiais. Segundo Sassaki (2002), todos esses termos são considerados inadequados por representarem valores agregados à pessoa. Como a expressão "portador de deficiência", por exemplo, que transmite a ideia de que a pessoa está portando algo que poderia se desfazer, como a deficiência não é algo que se desfaça, esse termo não é mais aceito.

Existem muitas dúvidas em relação ao modo de se referir a essas pessoas e, também, tem gerado bastante discussão entre grupos de inclusão. O termo sugerido por Sassaki (2002) foi também escolhido para fazer parte do texto da Convenção Internacional para Proteção dos Direitos e Dignidade das Pessoas com Deficiência, adquirido pela Assembleia Geral da Organização das Nações Unidas (ONU), em 2006. Chegaram à conclusão de que devem ser chamados de "pessoas com deficiência" em todos os idiomas.

\subsubsection{Surdo ou Deficiente Auditivo}

Na maioria das vezes, a sociedade fica com receio e apreensiva, sem saber se relacionar com pessoas surdas, muitas vezes, olham com inferioridade, e por falta de conhecimento acabam nomeando-os erroneamente. Como descreve Sassaki (2002), são tantas as terminologias (surdo-mudo, deficiente auditivo, portador de deficiência auditiva, portador de surdez, etc.) embasando em informações de diferentes presunções a respeito dos surdos, acabam confundindo a sociedade. 
Para o Surdo (a letra maiúscula se refere aqueles que pertencem à Comunidade Surda e se comunica por meio da língua de sinais), a terminologia "Deficiente Auditivo" não é aceita, porque o define segundo sua insuficiência de ouvir e não a presença de uma dinâmica cultural diferente. Esse termo é comumente usado na área da saúde e, geralmente, refere-se a uma pessoa que escuta menos de um ou dos dois ouvidos, mas não é considerada surda (PERLIN; MIRANDA, 2003).

Logo, ser Surdo é uma expressão cultural com suas políticas, histórias, subjetividades, pedagogias, identidades e outros, sendo assim, se identificam como Surdo, que formam características linguísticas, culturais e cognitivas, considerada como uma diferença e não uma deficiência. Como reflete Perlin e Miranda (2003, p. 217) (ambos pesquisadores surdos) sobre a diferença de ser surdo, "[...] vai desde o ser líder ativo nos movimentos e embates que envolvem uma determinada função ativa, até daqueles outros que iniciam contatos nos contornos de fronteiras". Esses contornos para os autores referem-se aos processos de hibridismo cultural, de integração e transição do surdo diante de uma comunidade predominantemente ouvinte.

\subsection{A formação acadêmica e profissional do surdo}

Lorenzetti (2001) analisou a compreensão de alguns profissionais da educação a respeito da inclusão de alunos surdos na escola regular, sendo que alguns deles puderam afirmar que não houve ganho algum aos educandos, pois eles não têm condições físicas para acompanhar os demais estudantes. A autora destaca ainda que a escola deve adequar-se ao aluno e não o contrário, de modo que a singularidade do estudante seja rejeitada.

A pesquisa realizada por Schuindt, Matos e Silva (2017) destaca que há a necessidade de materiais didáticos de acordo com as características do grupo, como também na inserção das práticas pedagógicas. Foi observado que a dificuldade dos alunos não está relacionada com o conteúdo apresentado em sala, mas sim, ao tipo de linguagem que está sendo utilizada. 
As dificuldades que os surdos enfrentam na educação brasileira, foi tema de redação da prova do Exame Nacional do Ensino Médio (Enem). O Instituto Nacional de Estudo e Pesquisas Educacionais Anísio Teixeira (Inep) explica que a abordagem do assunto foi uma forma de debater sobre as necessidades que essas pessoas enfrentam ao longo de sua trajetória escolar e também mostrar para a sociedade a importância das políticas inclusivas (AMARAL; SANTOS, 2017).

De acordo com Bisol et al. (2010), a inserção de qualquer estudante no Ensino Superior é um tanto desafiador. O surdo precisa se adaptar à vida acadêmica e ainda tentar contornar as falhas da trajetória escolar anterior. A universidade é um contexto desconhecido para esses jovens, pois o seu funcionamento, princípios e características são do mundo ouvinte. Ocorre que a maioria dos colegas e professores são ouvintes e desconhecem as especificidades relativas à surdez. Conforme estudo exploratório dos autores, a presença do intérprete em sala de aula, embora seja essencial, não é o suficiente.

Foster, Long e Snell (1999) relatam alguns problemas enfrentados pelos surdos no processo de ensino sendo: a) demora entre o que é falado e a tradução; b) a quebra do contato visual enquanto o professor escreve no quadro, ou quando se movimenta pela sala e lendo um documento, o que acaba impossibilitando a leitura labial; c) ocorre a perda de informação quando é preciso escolher entre olhar para o intérprete ou observar o professor enquanto manuseia algum objeto ou trabalha com imagens.

Tsuladze (2015) elenca outras dificuldades que os educandos surdos podem apresentar: a) conhecimento limitado de conteúdo dos intérpretes; b) intervalos de tempo e ritmo de instrução; c) comunicação limitada entre aluno surdo e professor ouvinte; d) participação restrita em discussões e conversas em sala de aula; e) dificuldade para atender múltiplas tarefas; f) dificuldades de compreensão de conteúdo; g) participação em discussões em sala de aula, entre outros.

\subsection{0 surdo no mundo do trabalho}

Com o surgimento do capitalismo a sociedade começou a ser vista como uma ampla mão de obra. E nela, somente homens "perfeitos" eram aceitos, sendo 
excluídas as pessoas com deficiência, incluindo os surdos. Dessa forma, ainda hoje se busca do "trabalhador ideal" deixando de lado os indivíduos considerados "fora do padrão" (SANTOS; SILVA, 2015).

Sobre a inclusão das pessoas com deficiência no mundo do trabalho, Oliveira (2007) apud Custódio (2012, p. 8) elucida que "A sociedade, as empresas e as próprias pessoas, às vezes, mesmo que não intencionalmente são um pouco preconceituosas". Estar empregado atualmente, não se trata somente de prover o sustento da família. O trabalho é fonte de reconhecimento social por proporcionar relacionamentos interpessoais possibilitando uma inclusão social e o sentimento de pertencer a um grupo. Esses anseios não pertencem apenas aos ouvintes, a Comunidade Surda tem os mesmos anseios querem fazer parte da sociedade, serem reconhecidos pelos próprios méritos (VIANA, 2016).

A Comunidade Surda só quer gozar de seus direitos constitucionais como qualquer ouvinte podendo ir e vir, estudar e trabalhar. Pois assim, como os ouvintes, os surdos também têm sonhos, almejam objetivos e querem ser vistos de forma igual com habilidades e potencial para se inserirem no mundo do trabalho (EVANGELISTA; SOUZA; TOZZO, 2014).

No entanto, não basta que o surdo seja contratado, é necessário que haja uma contribuição social da empresa, em especial o departamento de $\mathrm{RH}$. Isso porque a falta de comunicação reforça o preconceito de que são intelectualmente inferiores aos ouvintes. Esse preconceito os mantém isolados e, por mais que sejam qualificados, continuam exercendo funções simples e de baixa remuneração(CARVALHO, 2012).

\subsubsection{A importância da empregabilidade do Surdo}

O Portal Brasil (2017) apresenta a surdez como a segunda deficiência com o maior número de contratação formal no Brasil, com 70.389 trabalhadores em inúmeras áreas de atuação. Ainda, de acordo com essa plataforma, o Ministério do Trabalho reforça a importância da empregabilidade do surdo, promovendo ações para conscientização dos órgãos públicos e empresas privadas. Para que faça valer a Lei $n^{\circ} 8.213 / 91$, e ressaltando que o não cumprimento desta caracteriza em ato 
infracional levando à multa de acordo com a dimensão da organização. É importante destacar que o MT entende como discriminação 0 ato de não se adequar tanto fisicamente quanto por meio das tecnologias assistivas para que os trabalhadores cumpram suas funções de maneira independente.

Para colocar em prática a legislação trabalhista que estabelece contratação de pessoas com deficiência, as empresas têm recrutado principalmente as com surdez, pois não carecem de mudanças físicas na empresa. No entanto, essas organizações não estão aptas para receber o surdo, pois existe a diferença linguística, questão importante para o desempenho de suas funções (PRINCISVAL, 2015).

A autora supracitada, em sua pesquisa, realizou experimento em uma organização de São Paulo disposta a implantar um projeto de inclusão. Logo, recrutaram um surdo, mas para dar seguimento no projeto precisavam ultrapassar um obstáculo, ensinar LIBRAS para equipe de ouvintes que trabalharia com ele. Obstáculo superado com êxito, foi possível confirmar que a surdez não interfere na inclusão do surdo no mundo do trabalho, entretanto, é necessário, em contrapartida, que haja uma participação ativa por parte da empresa.

Bacelar (2017) apresenta um programa de empregabilidade que prepara tanto o surdo para inclusão no mundo do trabalho quanto a empresa para se tornar apta à receber esse novo funcionário. O programa reconhece as dificuldades encontradas tanto pela empresa quanto pelo o surdo. As empresas, geralmente, esperam que o surdo tenha a Língua Portuguesa como primeira língua, que seja, oralizado (utilize a voz para se comunicar), que faça leitura orofacial (ou leitura labial), com um bom nível de escolaridade e qualificação profissional. Porém, a realidade é controversa, demanda por parte da empresa, a incapacidade em tratar assuntos relacionados à surdez.

O surdo também sofre, pois fica com autoestima baixa por não conseguir se relacionar, não ter independência, acarretando a alta rotatividade por se sentir excluído e discriminado. Bacelar (2017) desenvolveu um programa em que tanto a empresa quanto o surdo passam por um preparo de um ano, antes de terem acesso 
à inclusão dele dentro da empresa, rompendo assim, com as barreiras linguísticas e discriminatórias.

\subsubsection{O papel da empresa no processo de inclusão socioeconômica do surdo}

Entre os anos de 1890 e 1920 surgiram os primeiros indícios do departamento de RH dentro das indústrias, suas funções eram ligadas somente a contratar, demitir e supervisionar seus trabalhadores. Atualmente suas atribuições vão muito além, sendo responsável pela análise e desenho dos cargos, recrutamento e seleção, treinamento de desenvolvimento, avaliação de desempenho e gerenciamento de remuneração. $\mathrm{O} \mathrm{RH}$ é a área da organização de nível estratégico que liga diretamente as políticas da organização com as práticas dos trabalhadores, tendo como objetivo, oferecer um âmbito de trabalho agradável e adequado aos trabalhadores para que sejam alcançados os alvos da organização (PACHECO, 2009).

O RH tem também como papel incluir a pessoa com deficiência na organização, participando como facilitador, promovendo uma humanização e conscientização dos trabalhadores, para que sejam vistas de forma igualitária (com limitações e habilidades) como qualquer outro indivíduo. É de responsabilidade desse departamento analisar os obstáculos e promover as adequações necessárias, evitando desconforto físico e/ou emocional (DUARTE; FRESCHI, 2013).

Diante das dificuldades para inserção do surdo no mundo do trabalho, Araújo, Silva e Sousa (2015) afirmam que seja importante que a empresa esteja ciente do universo da surdez e de suas capacidades, mais especificamente da sua linguagem. Quando é dada atenção necessária para o desenvolvimento do surdo fica explícito que a ausência da audição não o limita.

Princisval (2015) destaca ainda que o processo de inclusão é decorrente de uma série de fatores tendo como base a família e, posteriormente, um ensino bilíngue (ensino por meio da LIBRAS como primeira língua e a Língua Portuguesa (escrita) como segunda língua) adequado de maneira que não seja tardia. Todavia, de forma alguma isso diminui a responsabilidade da empresa no processo de 
inclusão, compreende-se que a deficiência não limita a pessoa nem a torna menos capaz, mas sim, o preconceito que ainda se faz presente nas pessoas.

Campos, Vasconcellos e kruglianskas (2013) ressaltam a importância de entender a diferença entre inserção e inclusão,

\begin{abstract}
A inserção requer tão somente práticas simples de recrutamento e seleção. Inclusão, ao contrário, requer planejamento para um programa que perpasse todos os processos de gestão de pessoas, promovendo o alinhamento estratégico horizontal entre eles e vertical com os macro-objetivos organizacionais, fazendo-se necessário que a área de Recursos Humanos passe a capitanear o processo [...] assessorada pela alta liderança e por outras áreas da empresa, em vez de ser a única responsável [...] (CAMPOS; VASCONCELLOS; KRUGLIANSKAS, 2013, p. 562).
\end{abstract}

Como solução, os mesmos autores propõem oito práticas de um programa de inclusão sendo elas: a) análise de acessibilidade; b) análise e definição do perfil do profissional com deficiência; c) sensibilização; d) recrutamento e seleção; e) avaliação da saúde ocupacional; f) treinamento; g) desenvolvimento de carreira e promoção; h) retenção. Em específico, a acessibilidade é tratada por Silva, Borges e Paiva (2018) como a equiparação de oportunidades e não como vantagem deste sobre aquele.

$\mathrm{Na}$ pesquisa de Souza (2015), sobre a qualidade de vida dentro das empresas, 107 trabalhadores com surdez se propuseram a responder um questionário com 35 questões. Concluiu que houve uma insatisfação por parte desses trabalhadores em todas as empresas pesquisadas, resultando em uma qualidade média, em relação ao ambiente de organizacional. É possível constatar ainda que há muito que ser feito para que os operários surdos alcancem o mesmo nível de oportunidades que os ouvintes. Salientando que os empreendimentos, muitas vezes, estão preocupados apenas em preencher cotas e não com a inclusão das pessoas com deficiência. 


\section{PROCEDIMENTOS METODOLÓGICOS}

A discriminação do tipo de pesquisa utilizada neste estudo se deu quanto à natureza, aos objetivos, à abordagem e os procedimentos. Quanto à sua natureza classifica-se como básica, pois não apresenta finalidades imediatas e produz conhecimento a ser utilizado em outras pesquisas (GIL, 2008).

Quanto aos seus objetivos, esse estudo é intitulado como sendo uma pesquisa descritiva, pois se pretendeu registrar e descrever os fatos observados sem interferir neles. Para Gil (2008, p. 28) "As pesquisas deste tipo têm como objetivo primordial a descrição das características de determinada população ou fenômeno ou o estabelecimento de relações entre variáveis".

Em relação à abordagem, utilizamos uma abordagem qualitativa "[...] interpretação de fenômenos e atribuição de significados" (PRODANOV; FREITAS, 2013, p. 128). Isso porque se pretendeu levantar dados qualitativos em relação aos funcionários surdos e às empresas do município que compõe a amostra.

Foi realizada uma pesquisa exploratória em seis empresas de um município do Centro-Oeste, do estado de Goiás, a fim de identificar aquelas que têm o surdo como funcionário. Diante deste levantamento foi possível estabelecer a amostragem. De acordo com Gil (2008, p. 94), "O pesquisador seleciona os elementos a que tem acesso, admitindo que estes possam, de alguma forma, representar o universo".

Como instrumento para a coleta de dados, foi utilizado um questionário, com 10 questões discursivas a serem aplicadas aos responsáveis pelo $\mathrm{RH}$ de seis empresas do município goiano. Realizou-se, também, uma entrevista semiestruturada, com 10 questões abertas, com três surdos localizados em uma empresa da região circunvizinha da cidade pesquisada. Essa ampliação para outra região se deu pela ausência de funcionários surdos nas empresas visitadas na pesquisa exploratória.

Para a entrevista, contamos com o auxílio de uma intérprete de LIBRAS $^{1}$ e um gravador em vídeo, para que as ideias fossem revistas posteriormente, se

\footnotetext{
${ }^{1}$ A Intérprete de LIBRAS é formada pela Associação de Surdos de Goiânia (ASG), desde 2010. Ela trabalha nesta área em uma universidade desse município do Centro-Oeste goiano, e nos acompanhou durante a entrevista sem nenhum ônus.
} 
necessário. Os dados recolhidos foram avaliados de maneira discursiva, correlacionando-os com o próprio Referencial Teórico que compõe esta pesquisa.

\section{ANÁLISE E DISCUSSÃO DOS DADOS}

Nesta seção serão analisados os dados coletados durante a pesquisa de campo. Primeiramente explicitaremos como se deu a pesquisa exploratória e depois a entrevista com os funcionários surdos.

\subsection{Pesquisa exploratória em empresas de uma cidade do Centro-Oeste goiano}

No dia 26 de outubro de 2018, no período matutino, foi realizada uma pesquisa exploratória em seis empresas em um município do Centro-Oeste do estado de Goiás. Essas foram escolhidas por terem o hábito de contratarem surdos, ou por já terem tido esse tipo de funcionário. Não serão divulgados os nomes destas por motivo de privacidade, foram visitadas com o intuito localizar surdos para a entrevista e para a aplicação de questionário com o responsável pelo $\mathrm{RH}$.

A abordagem realizada nas seis empresas foi concretizada de maneira igualitária. Apresentamo-nos como alunos do oitavo período de Administração, explicamos que estávamos realizando uma pesquisa de campo para o nosso artigo de conclusão de curso, e que para isso, precisaríamos falar com o responsável pelo $\mathrm{RH}$. Ao chegarmos ao nesse departamento éramos recebidos pelo responsável e aplicávamos o questionário. Os resultados dessa pesquisa exploratória se resumem nos parágrafos que seguem.

As seis empresas visitadas já tiveram surdos como funcionários, mas por motivos pessoais eles não trabalhavam mais. Os responsáveis pelo $\mathrm{RH}$ entrevistados disseram que os próprios surdos pediram demissão, de modo que nenhum deles foi demitido. E ressaltaram o quão difícil é a contratação desse público.

Duas das empresas visitadas chegaram a nos pedir indicações de pessoas surdas, pois estavam dispostas a contratar. As demais nos disseram que com a atual situação econômica do Brasil não seria feita nenhuma contratação no momento, mas que futuramente seria possível. Relataram ainda que a dificuldade de 
comunicação entre o surdo e os demais funcionários é bem difícil no começo, mas que depois de certo tempo ambos vão se acostumando a "gesticular" e "apontar" para se entenderem.

Outro assunto abordado, durante a aplicação do questionário com os responsáveis pelo $\mathrm{RH}$, foi relacionado aos surdos que já foram funcionários da organização. Questionamos quais cargos que estes ocupavam e como era o cotidiano deles na empresa. O cargo destinado a eles, nas as seis empresas, foi o de empacotador ou despachante de mercadoria, função essa que coloca o surdo numa situação mais reservada e que não exige comunicação direta com clientes. A rotina na empresa, segundo os participantes, muitas vezes ficava difícil, já que não havia ninguém na empresa para interpretar o que eles falavam. Por vez, havia a intervenção de terceiros ou familiares (presencialmente ou via celular) para fazer valer o diálogo.

Foi possível notar, durante a pesquisa, que as empresas buscam contratar pessoas que são surdas, mas que essas vagas, muitas vezes, ficam ociosas. Inferese que isso ocorra devido ao fato de que alguns surdos recebam "aposentadoria" ou um benefício da Assistência Social e que se trabalharem poderão perder essa benfeitoria.

Figura 1 - Foto da fachada do Ministério do Trabalho do município pesquisada

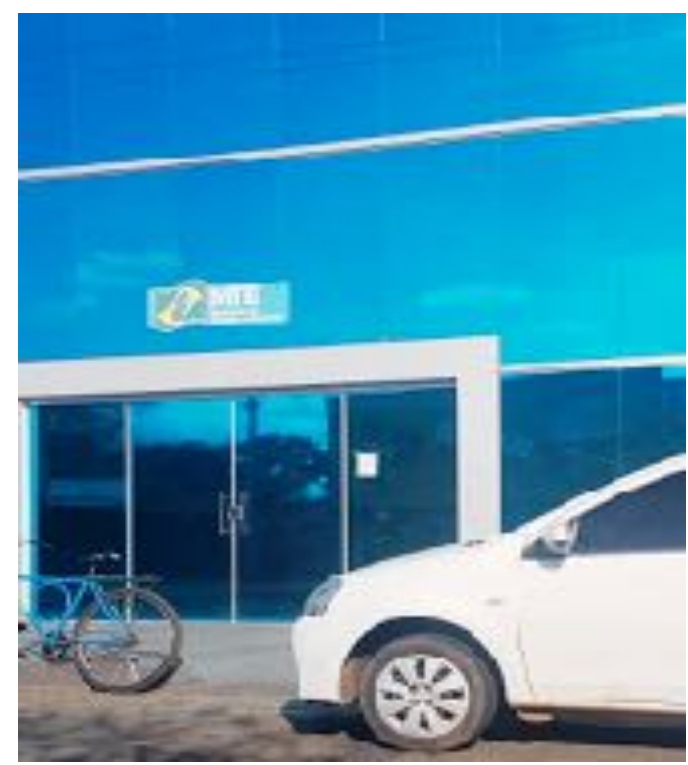

Fonte: Arquivo pessoal (2018) 
Notou-se, também, que esses empreendimentos não têm nenhuma preparação prévia para receber esse surdo. Isso vai ao encontro do que Souza (2015) diz que as empresas, muitas vezes, estão preocupadas apenas em preencher cotas e não estão atentas às necessidades do trabalhador com deficiência. Igualmente ao que Araújo (2015) defende que, no caso da surdez, muitas vezes, fica implícita as necessidades da pessoa. Sendo importante, nesse caso, que a contratante esteja ciente do universo da surdez e de sua capacidade de comunicação visual-motora.

Realizamos, também, uma visita ao Ministério do Trabalho (Figura 1), desse município do Centro-Oeste goiano, que ocorreu no dia 05 de junho de 2018, às 15 horas e 40 minutos. O objetivo foi averiguar se há alguma fiscalização do MT em relação à inclusão das pessoas com deficiência nas empresas. A resposta que obtivemos é que esse órgão não realiza nenhum tipo de inspeção nesse âmbito.

\subsection{Entrevista com os surdos}

A pretensão inicial era realizar a pesquisa apenas nesse município do CentroOeste goiano, no entanto, como visto da seção anterior, não se localizou empresas com surdos contratados, sendo necessário ampliar para uma empresa da região circunvizinha. No dia 15 de setembro de 2018, às 19 horas e 30 minutos, realizamos uma entrevista (Figura 2) com surdos nas dependências de uma universidade da cidade.

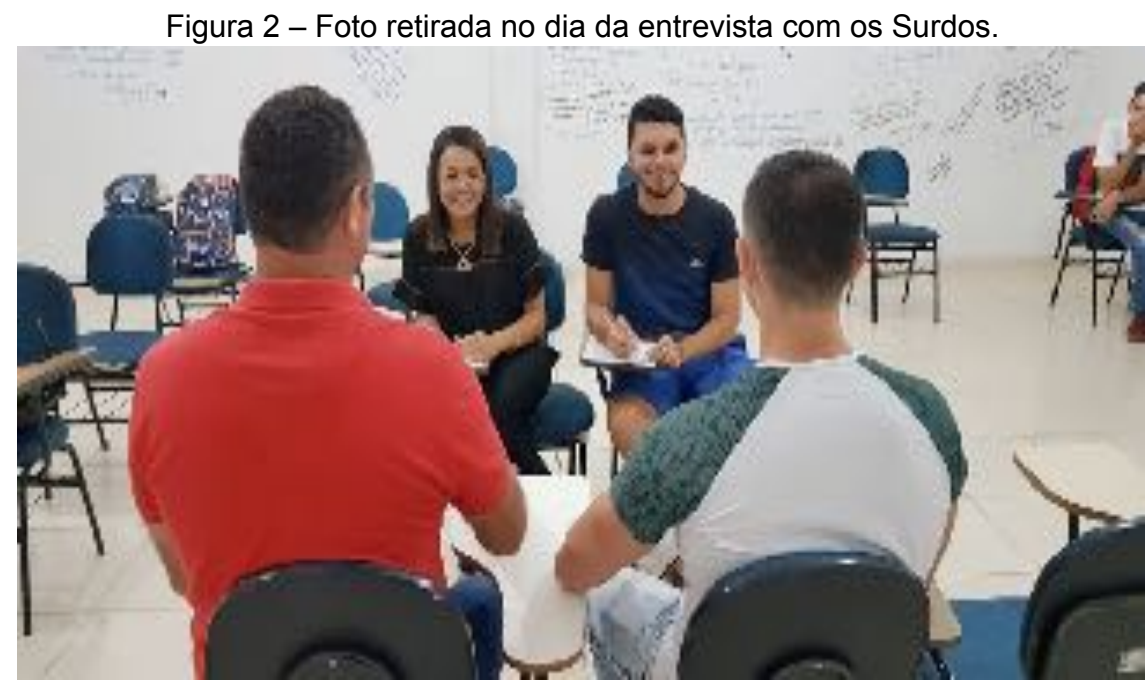

Fonte: Arquivo pessoal (2018). 
Dispuseram-se a participar, após receberem um convite por meio de um vídeo, em LIBRAS, enviado por nós, via WhatsApp. Essa mídia foi produzida pela intérprete de LIBRAS e enviada para cinco surdos. Dois deles compareceram presencialmente e um por meio de vídeo-chamada do aplicativo WhatsApp. A intérprete, também, nos auxiliou na tradução das perguntas e na interpretação das respostas.

Por questões éticas não citaremos o nome da empresa circunvizinha que os entrevistados trabalham e vamos nos referir a eles como: Surdo 1, Surdo 2 e Surdo 3. Iniciamos então a entrevista perguntando a idade, o cargo que exercem e o tempo de serviço. Podemos visualizar esses dados tanto no parágrafo que segue quanto no Quadro 1.

O Surdo 1 respondeu que tem 30 anos, e trabalha na empresa há 5 anos; o Surdo 2 falou que tem 41 anos e trabalha há 11 anos; o Surdo 3 disse ter 27 anos e trabalha há 11 anos nesse empreendimento. Todos os três trabalham na mesma empresa, no setor de CEDOC (Centro de documentação). Notamos que esse cargo vai ao encontro do que defende Carvalho (2012) confirmando que os surdos, geralmente, exercem funções simples, de baixa remuneração, com baixo nível de contato com clientes e que exige pouca comunicação.

\begin{tabular}{|c|c|c|c|}
\hline Entrevistados & Idade & Tempo de serviço & Cargo que ocupam \\
\hline Surdo 1 & 30 & 5 anos & \multirow{3}{*}{$\begin{array}{l}\text { Atuam na guarda, conservação e } \\
\text { disponibilização do acervo documental, } \\
\text { setor: CEDOC (Centro de documentação). }\end{array}$} \\
\hline Surdo 2 & 41 & 11 anos & \\
\hline Surdo 3 & 27 & 11 anos & \\
\hline
\end{tabular}

Foi perguntado se os surdos, foco dessa pesquisa, encontraram alguma dificuldade em conseguir um emprego, e ser contratado. As respostas podem ser vistas nos parágrafos que seguem:

O Surdo 1 respondeu que como já se passou muito tempo, não se lembrava exatamente, mas recordou que foi com a ajuda de um primo que fez cadastro na 
empresa, daí foi selecionado. Chegando à empresa perguntou ao supervisor: "Como que vou trabalhar? Não tem comunicação?". Encontrou uma pessoa surda que começou a explicar as funções de seu cargo. Com o tempo, mudou de cargo, e se perguntou: "E agora o que vou fazer?". Nessa nova função um ouvinte o ajudou, e ele "[...] foi olhando, foi memorizando, foi tentando e conseguindo ingressar [...]", só que a comunicação sempre foi um obstáculo. Explicou ainda que havia pessoas surdas que o entendiam mais e, que elas foram ajudando-o, no entanto, eram poucos ouvintes que conseguiam ajudá-lo.

O Surdo 2 falou que seu primeiro emprego foi em um supermercado e que seu cargo se destinava "carregar as entregas e mercadorias". Posteriormente houve uma mudança de cargo, ofereceram-no o cargo de empilhador. Essa função não exigia dele comunicação, e por isso, ele achava tranquilo. Devido o supermercado ter entrado em falência, procurou informações para o ingresso dele em outra empresa. Ingressou na mesma empresa do Surdo 1. No início, segundo ele, não teve dificuldade, pois havia outros surdos no local e esses o ajudaram na sua inclusão.

O Surdo 3 explicou que iniciou na empresa como jovem aprendiz, com 17 anos. A mãe foi quem ajudou no preenchimento e entrega de currículo. Relatou que foi bem difícil quando ingressou na empresa, pois a pessoa que o treinava para o serviço era ouvinte e não conhecia LIBRAS. Acrescentou ainda que quando entrou nessa organização tinha em torno de 10 surdos e que hoje, tem apenas cinco, sendo que três no setor que trabalha.

Perguntamos se os surdos têm o sonho de trabalhar em alguma outra profissão. O Surdo 1 disse estar satisfeito com a sua função e que não se vê fazendo outra coisa. O Surdo 2 respondeu que gostaria de trabalhar no supermercado novamente, só que em outra função, como por exemplo conferente de mercadoria, e não tem nenhum sonho de trabalhar em alguma profissão. O Surdo 3 relatou que tem o sonho de fazer biomedicina, mas sabe que isso será um grande desafio, já que tem que cuidar do filho que tem cinco anos.

Investigamos se a maior dificuldade dos Surdos no mercado de trabalho é relativa à comunicação em LIBRAS ou à Língua Portuguesa? Explicaram que no 
ambiente de trabalho as pessoas ouvintes utilizam muito a "apontação" e gestos que acabam ajudando na comunicação, mas que não é suficiente. Disseram que a comunicação por meio de sinais é quase nula, já que não há ninguém dentro da empresa que saiba ou utilize a língua de sinais para se comunicar. Expuseram ainda que o Português dificulta bastante, porque muitas palavras são desconhecidas por eles, e não conseguem entender. Relataram que há pessoas que pensam que ao escrever, eles vão entender tudo, mas que não é bem assim que acontece, pois tem palavras que os surdos só entendem o significado.

Indagamos se alguma vez a empresa já pediu para eles ficarem em casa, por achar que aquela atividade que estavam exercendo era irrelevante diante de sua falta de audição. Responderam que isso já aconteceu com eles. O Surdo 1 relatou que questionou com a pessoa porque não poderia ir ao trabalho, e a pessoa respondeu "Porque você é Surdo", disse que ficou bastante triste.

Indagamos se eles sentem que seu trabalho dentro da empresa é reconhecido. Responderam que procuram fazer o trabalho sempre certo, e as pessoas geralmente reconhecem seu esforço. Perguntamos, também, se a empresa promove incentivos para o crescimento deles dentro da corporação. Contestaram que é muito difícil de acontecer, mas gostaria muito, pois eles têm ciência de que precisam aprender mais. Quando questionados sobre os treinamentos dentro da empresa, e como se sentem nesse âmbito (inseridos ou excluídos), afirmaram que existem poucos treinamentos e que quando oferecem não são inseridos, e mesmo questionando que gostariam de participar são ignorados.

Finalizamos a entrevista perguntando, se eles fossem donos de uma empresa quais as atitudes que tomariam para mudar a visão das pessoas em relação aos surdos. Como eles entendem tudo "ao pé da letra" disseram que, para isso, teriam que ter um diploma para assumir esse alto cargo. Reformulada a pergunta pela intérprete, os entrevistados responderam que ao contratar pessoas com surdez, primeiramente, trocariam ideias com elas antes, para ver qual a melhor forma de comunicação. Assim seria possível encaminhar e orientá-los corretamente. 


\section{CONSIDERAÇÕES FINAIS}

Com base na pesquisa bibliográfica deste estudo fica de forma explícita a relevância do mencionado estudo, de maneira que expande uma visão ética, humana para refletir sobre as contribuições socioeconômicas da Comunidade Surda. Dentre as leituras de artigos e estudos em bases científicas, fica clara a necessidade de trazer tais assuntos para o meio acadêmico. De maneira que se possa reverter as barreiras e dificuldades para a inclusão do surdo no mercado de trabalho, trazendo à tona um assunto que ainda hoje é desafiador e traz discussões no meio socioeconômico, mas com a finalidade de superar impedimentos e agregar valores.

Esclareceu-se com as visitas às empresas que compuseram a amostra e ao Ministério do Trabalho que os surdos são os mais requisitados por não necessitarem de mudanças físicas nas organizações. Porém, esses empreendimentos estão despreparados para recebê-los, pois visam somente sua contratação para suprir uma cota que é demandada pelo governo e não fiscalizada. Ainda assim, o preenchimento destas vagas se torna difícil, pois muitos preferem receber o benefício de invalidez, já que os salários se equiparam a eles.

Por meio da entrevista com os surdos, foi possível constatar os desafios e dificuldades encontrados em seu cotidiano, mas não por serem incapazes de realizar algo, muito pelo contrário, pela falta de apoio por parte dos ouvintes. Com os entrevistados foi possível ver que o aprendizado deles dentro da empresa só foi possível porque já havia surdos trabalhando no mesmo local, os quais ensinaram as atividades a serem desenvolvida no departamento, já que não havia nenhum ouvinte que soubesse LIBRAS para dar esse auxílio. A dificuldade de comunicação na sua língua é o maior obstáculo para sua contratação e permanência no emprego.

Em relação aos objetivos, levantados no início deste estudo, conseguimos apontar as dificuldades encontradas na inserção do surdo no mercado de trabalho, apresentando-os tanto na pesquisa bibliográfica quanto na de campo. Nesta última, os entrevistados nos apontaram os desafios encontrados em seu dia a dia, até mesmo após a sua inserção na empresa. Nossa hipótese inicial era de que as 
empresas estavam despreparadas para esse tipo de inclusão, e ela pode ser constatada tanto por relatos dos surdos, quanto pelos responsáveis do RH.

Acreditamos, inicialmente, que seria fácil encontrar empresas que tivessem surdos trabalhando, já que se trata de uma lei. No entanto, a realidade é muito diferente, pois algumas organizações não cumprem a legislação e outras ficam com vagas ociosas, por falta da demanda desse público. Reconhecemos que a pesquisa precisa ser mais aprofundada visitando mais empresas e, até mesmo, expandindo para outros municípios.

Pensando nisso, recomendamos aos futuros pesquisadores dessa temática que ampliem a amostra, não a restringindo por município. Realizar entrevistas via vídeo-chamada nos pareceu um bom recurso, desde que acompanhados por um intérprete de LIBRAS. Acreditamos que a ampliação dessa pesquisa acarretará em maior relevância, pois atingirá um território maior e uma quantidade maior de surdos a serem entrevistados, obtendo assim uma visão mais ampla da atual situação dessas pessoas no mundo do trabalho. Além disso, deixamos como sugestão que sejam entrevistadas as empresas que contrataram esses surdos, para oportunizar o discurso de ambas as partes.

\section{REFERÊNCIAS}

AMARAL, S. C.; SANTOS, R. M. O surgimento da LIBRAS e sua importância na comunicação e educação dos surdos. 2017. Disponível em:<https://editorarealize.com.br/ revistas/conedu/trabalhos/TRABALHO_EV073_MD1_SA10_ID2368_16102017221540.pdf>. Acesso em: 31 mar. 2018.

ARAÚJO, D. M. S.; SILVA, M. C.; SOUSA, W. P. A. A influência da LIBRAS no processo educacional de estudantes surdos em escola. 2015. Disponível em: <http:// files.portaldossurdos.webnode.pt/ 2000025134 d 0 d 14 e 084 / a\%20influncia\%20da\%20libras $\% 20$ no\%20processo\%20educacional\%20de $\% 20$ estudantes $\%$ 20surdos\%20em\%20escola\%20regular.pdf>. Acesso em: 05 abr. 2018.

BACELAR, G. B. Derdic - Programa de Empregabilidade. Preparação e Inclusão de Surdos no Mercado de Trabalho. 2017. Disponível em: <http://www.cvs.saude.sp.gov.br/up/ Prepara\%C3\%A7\%C3\%A30\%20e\%20Inclus\%C3\%A30\%20de\%20Surdos\%20no\%20Merca do\%20de\%20Trabalho.pdf>. Acesso em: 02 mai. 2018.

BISOL, C. A.; VALENTINI, C. B.; SIMIONI, J. L.; ZANCHIN, J. Estudantes Surdos no Ensino Superior: Reflexões sobre a inclusão. Cadernos de Pesquisa. V.40. n.139, jan./abr.2010. 
BRASIL. Lei $n^{\circ} 8.213$, de 24 de julho de 1991. Dispõe sobre os Planos de Benefícios da Previdência Social e dá outras providências. Diário Oficial da União - DOU: 25.7.1991.

Lei $n^{\circ} 10.436$, de 24 de abril de 2002. Dispõe sobre a Língua Brasileira de Sinais Libras e dá outras providências. Diário Oficial da União - DOU: 25/04/2002.

Decreto $n^{\circ} 5.296$, de 2 de dezembro de 2004. Regulamenta as Leis $n^{\circ} 10.048$, de 8 de novembro de 2000 , que dá prioridade de atendimento às pessoas que especifica, e 10.098, de 19 de dezembro de 2000, que estabelece normas gerais e critérios básicos para a promoção da acessibilidade das pessoas portadoras de deficiência ou com mobilidade reduzida, e dá outras providências. Diário Oficial da União - DOU: 3.12.2004.

Decreto $n^{\circ} 5626$, de 22 de dezembro de 2005. Regulamenta a Lei $n^{\circ} 10.436$, de 24 de abril de 2002, que dispõe sobre a Língua Brasileira de Sinais - LIBRAS, e o artigo 18 da Lei $n^{\circ}$ 10098, de 19 de dezembro de 2000. Diário Oficial da União - DOU: 23.12.2005.

CAMPOS, J. G. F.; VASCONCELLOS, E. P. G.; KRUGLIANSKAS, G. Incluindo pessoas com deficiência na empresa: estudo de caso de uma multinacional brasileira. Revista Administração, São Paulo, v.48, n.3, p.560-573, jul./ago./set. 2013.

CARVALHO, R. P. Q. O surdo e o mercado de trabalho: conquistas e desafios. Anais do IV Seminário Eniac 2012. Disponível em: <https://ojs.eniac.com.br/index.php/Anais/article/ download/91/96>. Acesso em: 25 abr. 18.

CUSTÓDIO, A. C. C. A inserção do surdo no mercado de trabalho, frente às políticas públicas de inclusão: as duas faces de uma mesma moeda. 2012. Disponível em: <http:// www.cepae.faced.ufu.br/sites/cepae.faced.ufu.br/VSeminario/trabalhos/295_1_2.pdf>. Acesso em: 26 abr. 18.

DUARTE, Y. M.; FRESCHI, J. C. O papel dos recursos humanos na contratação de Pessoas com Deficiência-PcD. Revista terceiro setor. V.7, n.1, 2013.

EVANGELISTA, F. F. G.; SOUZA, T. F. C.; TOZZO, C. A inclusão do surdo no mercado de trabalho de acordo com sua capacidade profissional. Revista Ensaios \& Diálogos - № 7 janeiro/dezembro de 2014, p. 49-57.

FOSTER, S.; LONG, G.; SNELL, K. Inclusive instruction and learning for deaf students in postsecondary education. Journal of Deaf Studies and Deaf Education. Oxford, v.4, n.3, p. 225-235, Summer, 1999.

GESSER, A. LIBRAS? Que língua é essa?: crenças e preconceitos em torno da língua de sinais e da realidade surda. São Paulo: Parábola Editorial, 2009.

GIL, A. C. Como elaborar projetos de pesquisa. 4. ed. São Paulo: Atlas, 2008.

IBGE. Censo demográfico 2010. Características Gerais da População. Resultados da Amostra. Disponível em: <https://censo2010.ibge.gov.br/>. Acesso em 28 fev. 2019.

LORENZETTI, M. L. A inclusão do aluno surdo no ensino regular: a voz das professoras. Dissertação de mestrado em Educação Científica e Tecnológica. Universidade de Santa Catarina. 2001.

PACHECO, M. S. Evolução da gestão de Recursos Humanos: um estudo de 21 empresas. 2009. Disponível em: <file:///C:/Users/admin/Downloads/ MarcelaSoaresPacheco\%20(1).pdf>. Acesso em: 19 mai. 2018. 
PERLIN, G. T. T.; MIRANDA, W. Surdos: o narrar e a política. Revista Ponto de Vista, Florianópolis, n.05, p. 217-226, 2003.

PORTAL BRASIL. Quase $\mathbf{8 0}$ mil pessoas com deficiência auditiva têm carteira assinada no Brasil. 2017. Disponível em: <http://www.brasil.gov.br/economia-e-emprego/2017/09/ quase-80-mil-pessoas-com-deficiencia-auditiva-tem-carteira-assinada-no-brasil>. Acesso em: 01 maio de 18

PRINCISVAL, A. R. A contribuição da pessoa surda no mercado de trabalho. Monografia de especialização em Educação Especial e Inclusiva, da Universidade Cândido Mendes da Cidade do Rio de Janeiro, 2015.

PRODANOV, C. C.; FREITAS, E. C. Metodologia do trabalho científico: métodos e técnicas da pesquisa e do trabalho acadêmico. 2. ed. Novo Hamburgo: Feevale, 2013.

SANTOS, N. C.; SILVA, C. A importância da inclusão do deficiente auditivo na cultura da organização. Revista Diálogos Interdisciplinares. 2015, vol.4, nº.1 ISSN 2317-3793.

SASSAKI, R. K. Terminologia sobre deficiência na era da inclusão. Revista Nacional de Reabilitação, São Paulo, ano 5, n. 24, jan./fev. 2002.

SCHUINDT, C. C.; MATOS, C. F.; SILVA, C. S. Estudo de caso sobre as dificuldades de aprendizagem de alunos surdos na disciplina de Química. ACTIO, Curitiba, v. 2, n. 1, p. 282-303, jan./jul. 2017.

SILVA, C. P.; BORGES, R. L.; PAIVA, L. D. Acessibilidade de alunos com deficiência nas aulas de Educação Física. Beau-Bassin/Maurícias: NEA, 2018.

SOUZA, R. M. Análise da qualidade de vida no trabalho dos surdos em atividade nas empresas da cidade de Ponta Grossa - Paraná. Dissertação de Mestrado apresentada ao Programa de Pós-Graduação em Engenharia de Produção da Universidade Tecnológica Federal do Paraná. 2015.

TSULADZE, Maia. Teaching and Learning of Deaf Students in Ordinary Vocational Education Setting. Master's Thesis in the Philosophy in Special Needs Education Department of Special Needs Education. Faculty of Educational Sciences the University Of Oslo The Georgia Case. 2015. Disponível em: <https://www.duo.uio.no/bitstream/handle/ 10852/49455/Maia-Tsuladze-Masters-Thesis-SNE-4390.pdf?sequence=1>. Acesso em: 22 mai. 2018.

VIANA, A. S. A inserção dos surdos no mercado de trabalho: políticas públicas, práticas organizacionais e realidades subjetivas. Revista Gestão e Planejamento, Salvador, v. 17, n. 2, p. 214-232, maio/ago. 2016. 